\title{
Dynamic Analysis of Multi-unit Hydropower Systems in Transient Process
}

\author{
Huanhuan $\mathrm{Li}^{1}$, Diyi Chen ${ }^{1,2, *}$, Beibei Xu${ }^{1}$, Silvia Tolo ${ }^{3}$, Edoardo Patelli ${ }^{3}$
}

${ }^{1}$ Institute of Water Resources and Hydropower Research, Northwest A\&F University, Shaanxi Yangling 712100, P. R. China

${ }^{2}$ Australasian Joint Research Centre for Building Information Modelling, School of Built Environment, Curtin University, WA, 6102, Australia

3 Institute for Risk and Uncertainty, University of Liverpool, Peach Street, Chadwick Building, Liverpool L69 7ZF, UK

\section{Corresponding author: Diyi Chen}

Mailing Address: ${ }^{1}$ Institute of Water Resources and Hydropower Research, Northwest A\&F University, Shaanxi Yangling 712100, China

Telephones: 086-181-6198-0277

E-mail: diyichen@nwsuaf.edu.cn

\begin{abstract}
This paper addresses a mathematical model and dynamic analysis of multi-unit hydropower systems in transient process. In this work, the first unit is assumed to be subject to a sudden load decrease, while the second unit runs with load. A approach to the description of the six stochastic dynamic transfer coefficients of the hydro-turbine is proposed for the second unit. Moreover, a novel dynamic model for the multi-unit hydropower system, able to take into account the eventual occurrence of water hammer in the penstock and the nonlinearity of the generator, is introduced. Also, a numerical application is analyzed in order to investigate the effectiveness of the approach proposed and the dynamic characteristics of the system under study. Finally, a comparative analysis is proposed in order to validate the proposed system. The methods and results implemented in this work provide theoretical tools to guarantee the stable operation of hydropower stations.
\end{abstract}

Keywords multi-unit hydropower systems, stochastic transfer coefficients, transient process, dynamics 


\section{Introduction}

In common practice, the multi-unit hydropower system (MUHS) is widely used in medium hydropower stations and pumped storage power stations in order to reduce the cost of construction units [1-10]. MUHSs are complex hydraulic-mechanical-electro dynamic systems that contain some nonlinear factors like the water-hammer effect in penstock and the self-excited vibration. That is, MUHS plays a key role in ensuring the safety and stability of hydropower plants [11-18]. Therefore, the study of multi-unit hydropower systems results extremely relevant.

In the existent literature, few studies are dedicated to the investigation of multi-unit hydropower systems. In addition to this, most of these works focus mainly on the modeling of hydropower systems assuming steady state [14-27]. Conversely, the research referred to transient processes is quite limited $[17,22]$. In spite of this, in the actual operation of hydropower stations, transient processes are directly related to the dynamic behavior of hydropower plants [28-34]. Therefore, it is of crucial importance to fully understand and model the dynamic characteristics of multi-unit hydropower systems in transient process.

For these reasons, in order to study nonlinear laws and behaviors of the dynamic MUHS, nonlinear dynamic that can accurately predict evolution process is therefore introduced into the hydropower system to queries complex nonlinear problems in system. In this work, the behavior of a MUHS with two units subject to transient process is investigated. The main novelty of this paper consists of three aspects: first, an innovative approach to the identification of six stochastic dynamic transfer coefficients of the hydro-turbine is proposed for the modeling of the variation characteristics of the second unit (which, as mentioned above, runs normally at the beginning of the transient process). Second, a novel nonlinear dynamic mathematical model of multi-unit hydropower systems for the transient process, considering water hammer and the nonlinearity of the generator is 
proposed. Third, the method implemented is numerical applied to a hypothetical system in order to study its dynamic behavior. Finally, a comparative analysis is proposed in order to validate the proposed system.

The paper is organized as follows: in Section 2, the novel nonlinear dynamic mathematical model is established. Section 3 analyzes the dynamic behavior of the system adopting the developed approach. In Section 4, a comparative analysis of the system is carried out in order to validate the proposed system. Finally, conclusions and further discussion are introduced in Section 5 and 6 respectively.

Table 1 Variables of the multi-unit hydropower system.

\begin{tabular}{|c|c|}
\hline Symbol & Quantity \\
\hline$b_{t}$ & height of the guide vane, $\mathrm{m}$ \\
\hline$D$ & damping coefficient \\
\hline$D_{1}$ & runner diameter of the hydro-turbine, $\mathrm{m}$ \\
\hline$d$ & constant of the flow passage component \\
\hline$E_{q}^{\prime}$ & transient internal voltage of armature, p.u. \\
\hline$e_{m x}, e_{m y}, e_{m h}$ & $\begin{array}{l}\text { partial derivatives of the hydro-turbine torque with respect to the } \\
\text { hydro-turbine speed, the hydro-turbine guide vane and the hydro-turbine } \\
\text { head, p.u. }\end{array}$ \\
\hline$e_{q x}, e_{q y}, e_{q h}$ & $\begin{array}{l}\text { partial derivatives of the flow with regard to the hydro-turbine speed, the } \\
\text { hydro-turbine guide vane and the hydro-turbine head, p.u. }\end{array}$ \\
\hline$F$ & runner outlet area, $\mathrm{m}^{2}$ \\
\hline$H$ & hydro-turbine head, $\mathrm{m}$ \\
\hline$h$ & deviation of the hydro-turbine head, p.u. \\
\hline$h_{w i}$ & pipeline characteristic coefficient of the branch pipe $i(i=1,2)$, s \\
\hline$k_{d}$ & differential adjustment coefficient \\
\hline$k_{i}$ & integral adjustment coefficient \\
\hline$k_{p}$ & proportional adjustment coefficient \\
\hline$M_{t}$ & mechanical torque of the hydro-turbine, N.m \\
\hline$m_{e}$ & electromagnetic torque of the generator, N.m \\
\hline$m_{t}$ & deviation of the mechanical torque of the hydro-turbine, p.u. \\
\hline$n$ & hydro-turbine speed, $\mathrm{rad} / \mathrm{s}$ \\
\hline$P_{e}$ & electromagnetic power of the generator, p.u. \\
\hline$Q$ & hydro-turbine flow, $\mathrm{m}^{3} / \mathrm{s}$ \\
\hline$q$ & deviation of the hydro-turbine flow, p.u. \\
\hline$r$ & runner intermediate flow surface radius, $\mathrm{m}$ \\
\hline$T_{a b}$ & mechanical starting time, $\mathrm{s}$ \\
\hline$T_{w i}$ & water starting time of the branch pipe $i(i=1,2), \mathrm{s}$ \\
\hline
\end{tabular}




\begin{tabular}{cc}
$T_{w p}$ & water starting time of the common penstock, $\mathrm{s}$ \\
$u$ & output of the regulator \\
$V_{s}$ & voltage of infinite bus, p.u. \\
$W$ & generator rotor speed, rad/s \\
$x$ & deviation of the hydro-turbine speed, p.u. \\
$x_{d}$ & direct axis transient reactance, p.u. \\
$x_{L}$ & transmission line reactance, p.u. \\
$x_{q}$ & quartered axis reactance, p.u. \\
$x_{T}$ & short-circuit reactance of transformer, p.u. \\
$Y$ & main servomotor stroke, rad \\
$y$ & deviation of the guide vane opening, p.u. \\
$z$ & guide vane opening, rad \\
$\alpha$ & guide vane discharge angle, rad \\
$\beta$ & runner intermediate flow surface angle, rad \\
$\delta$ & rotor angle, rad \\
$\omega$ & deviation of the generator rotor speed, p.u. \\
subscript $*$ & optimum operating condition \\
subscript $R$ & actual value of steady condition \\
subscript 0 & actual value of steady condition \\
\hline \hline
\end{tabular}

\section{Model of multi-unit hydropower systems}

A multi-unit hydropower system consists mainly of a synchronous generator, a hydro-turbine, a governor and a penstock, as shown in Fig. 1 [18].

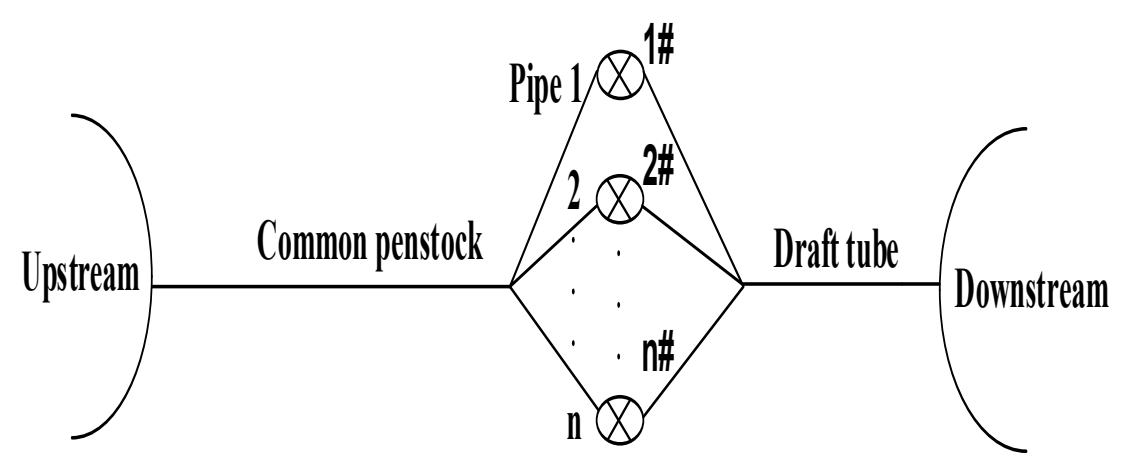

Fig. 1. Diagram of the structure of a multi-unit hydropower system.

\subsection{Mathematical model of Francis hydro-turbines}

The dynamic characteristics of a Francis hydro-turbine [12] can be expressed as

$$
\left\{\begin{array}{l}
M_{t}=M_{t}(H, n, z) \\
Q=Q(H, n, z)
\end{array},\right.
$$

where $M_{t}, Q, H, n$ and $z$ denote the mechanical torque of the hydro-turbine, the hydro-turbine 
flow, the hydro-turbine head, the hydro-turbine speed and the guide vane opening, respectively.

Based on Taylor series expansion, Eq. (1) can be rewritten as

$$
\left\{\begin{array}{l}
\frac{M_{t}-M_{t 0}}{M_{t R}}=\frac{\partial \frac{M_{t}}{M_{t R}}}{\partial \frac{n}{n_{R}}} \frac{n-n_{0}}{n_{R}}+\frac{\partial \frac{M_{t}}{M_{t R}}}{\partial \frac{z}{z_{\max }}} \frac{z-z_{0}}{z_{\max }}+\frac{\partial \frac{M_{t}}{M_{t R}}}{\partial \frac{H}{H_{R}}} \frac{H-H_{0}}{H_{R}} \\
\frac{Q-Q_{0}}{Q_{R}}=\frac{\partial \frac{Q}{Q_{R}}}{\partial \frac{n}{n_{R}}} \frac{z-z_{0}}{n_{R}}+\frac{\partial \frac{Q}{Q_{R}}}{\partial \frac{z}{z_{\max }}} \frac{z-z_{0}}{z_{\max }}+\frac{\partial \frac{Q}{Q_{R}}}{\partial \frac{H}{H_{R}}} \frac{z-z_{0}}{H_{R}}
\end{array}\right.
$$

where subscripts $R$ and 0 denote the actual value of rated condition and the actual value of steady condition, respectively. Here, $\frac{\partial \frac{M_{t}}{M_{t R}}}{\partial \frac{n}{n_{\max }}}=\frac{\partial m_{t}}{\partial x}, \frac{\partial \frac{M_{t}}{M_{t R}}}{\partial \frac{z}{z_{\max }}}=\frac{\partial m_{t}}{\partial y}, \frac{\partial \frac{M_{t}}{M_{t R}}}{\partial \frac{H}{H_{\max }}}=\frac{\partial m_{t}}{\partial h}, \frac{\partial \frac{Q}{Q_{R}}}{\partial \frac{n}{n_{\max }}}=\frac{\partial q}{\partial x}$, $\frac{\partial \frac{Q}{Q_{R}}}{\partial \frac{z}{z_{\max }}}=\frac{\partial q}{\partial y}$ and $\frac{\partial \frac{Q}{Q_{R}}}{\partial \frac{H}{H_{\max }}}=\frac{\partial q}{\partial h}$

Subsequently, Eq. (2) can be expressed as

$$
\left\{\begin{array}{l}
\frac{\Delta M_{t}}{M_{t R}}=\frac{\partial m_{t}}{\partial x} \frac{n-n_{0}}{n_{R}}+\frac{\partial m_{t}}{\partial y} \frac{z-z_{0}}{z_{\max }}+\frac{\partial m_{t}}{\partial h} \frac{H-H_{0}}{H_{R}} \\
\frac{\Delta Q}{Q_{R}}=\frac{\partial q}{\partial x} \frac{z-z_{0}}{n_{R}}+\frac{\partial q}{\partial y} \frac{z-z_{0}}{z_{\max }}+\frac{\partial q}{\partial h} \frac{z-z_{0}}{H_{R}}
\end{array} .\right.
$$

Based on ref. [12], assuming that the guide vane opening $z$ is equal to the main servomotor stroke $Y$. Thus, Eq. (3) can be written as

$$
\left\{\begin{array}{c}
m_{t}=e_{m w} x+e_{m y} y+e_{m h} h \\
q=e_{q w} x+e_{q y} y+e_{q h} h
\end{array},\right.
$$

where $m_{t}, q, h, x$ and $y$ refer to the corresponding deviations of $M_{t}, Q, H, n$ and $a$, respectively. $e_{m w}=\frac{\partial m_{t}}{\partial x}, e_{m y}=\frac{\partial m_{t}}{\partial y}$ and $e_{m h}=\frac{\partial m_{t}}{\partial h}$ are the partial derivatives of the hydro-turbine torque with respect to the hydro-turbine speed, the hydro-turbine guide vane and the 
hydro-turbine head. Similarly, $e_{q w}=\frac{\partial q}{\partial x}, e_{q y}=\frac{\partial q}{\partial y}$ and $e_{q h}=\frac{\partial q}{\partial h}$ are the partial derivatives of the flow with regard to the hydro-turbine speed, the hydro-turbine guide vane and the hydro-turbine head, respectively.

\subsection{Penstock model considering water hammer}

Generally, the water supply mechanism for the penstock system includes a hydro-turbine set with an individual penstock, multi-hydro-turbine sets with shared common penstock and multi-hydro-turbine sets with shared multi-penstocks [18]. In this paper, the multi-hydro-turbine sets with shared common penstock are considered, as shown in Fig. 2.

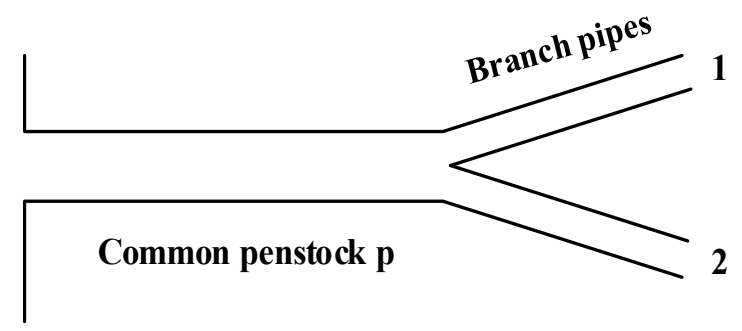

Fig. 2. Penstock system with common penstock and several bifurcated pipes.

This study focuses mainly on the analysis of hydropower systems with two units. Let $\mathrm{p}$ refer to the common penstock and 1 and 2 to two branch pipes. The transfer function of the water hammer for an arbitrary branch pipe [17] can be expressed as

$$
G_{D i}=\frac{-T_{w p} s-T_{w i} s}{1+\frac{T_{w i} T_{w p} s^{2}}{4 h_{w i}^{2}}},
$$

where $T_{w p}$ is the water starting time of the common penstock. $T_{w i}$ and $h_{w i}$ represent the water starting time and the pipeline characteristic coefficient of the branch pipe $i(i=1,2)$ respectively.

In light of previous studies (see ref. [17]), the differential equation of Eq. (5) can be written as

$$
h^{\prime \prime}+a_{1} h=b_{1} q^{\prime}
$$


Meanwhile, the state-space equations of Eq. (6) can be written as

$$
\left\{\begin{array}{l}
x_{1}^{\prime}=x_{2}+b_{1} q \\
x_{2}^{\prime}=-a_{1} x_{1}, \\
x_{1}=h
\end{array},\right.
$$

where $a_{1}=\frac{4 h_{w i}^{2}}{T_{w i} T_{w p}}, b_{1}=-4 \frac{h_{w i}^{2} T_{w p}+h_{w i}^{2} T_{w i}}{T_{w i} T_{w p}}$.

\subsection{Mathematical model of the generator}

In this subsection, a third-order model of the generator is considered. Its dynamic characteristic expressions $[18,37]$ can be written as

$$
\left\{\begin{array}{lcll}
i & \cdots u & \\
i & 1 & \left.-p_{e}-D \omega\right) \\
& T_{a b}^{\prime} & \\
\dot{i}_{q} & & T_{d} & \frac{x_{d \Sigma}}{x_{d \Sigma}^{\prime}} E_{q}^{\prime}+\frac{\omega_{0}}{T_{d}} \frac{x_{d \Sigma}-x_{d \Sigma}^{\prime}}{x_{d \Sigma}^{\prime}} V_{s} \cos \delta+\frac{\omega_{0}}{T_{d}} E_{f}
\end{array},\right.
$$

where $\delta, \omega, D, T_{a b}, P_{e}, E_{q}^{\prime}, E_{f}$ and $T_{d}$ refer respectively to the rotor angle, the relative deviation of the generator speed, the damping coefficient, the mechanical starting time, the electromagnetic power of the generator, the transient internal voltage of the armature, the output of excitation controller and the transient time constant of axis $d$. In Eq. (8), the electromagnetic power of the generator $P_{e}$ can be calculated with the following formula

$$
P_{e}=\frac{E_{q}^{\prime} V_{s}}{x_{d \Sigma}^{\prime}} \sin \delta+\frac{V_{s}^{2}}{2} \frac{x_{d \Sigma}^{\prime}-x_{q \Sigma}}{x_{d \Sigma}^{\prime} x_{q \Sigma}} \sin 2 \delta
$$

where $E_{q}^{\prime}, V_{s}, x_{d}^{\prime}$ and $x_{q}$ are respectively the transient internal voltage of armature, the voltage of infinite bus, the direct axis transient reactance and the quartered axis reactance. $x_{d \Sigma}^{\prime}$ and $x_{q \Sigma}$ in Eq. (9) can be expressed as

$$
\left\{\begin{array}{l}
x_{d \Sigma}^{\prime}=\because \quad \begin{array}{c}
1 \\
2^{-x_{L}} \\
x_{q \Sigma}=x_{q}+x_{T}+\frac{1}{2} x_{L}
\end{array}
\end{array}\right.
$$


where $x_{T}$ and $x_{L}$ are the short-circuit reactance of the transformer and the transmission line reactance, respectively.

\subsection{Mathematical model of the hydraulic speed regulation system}

Both unit 1 and unit 2 of the MUHS considered in this study use a parallel PID governor. Assuming the governor system to be a non-disturbance system, the dynamic characteristics of the hydraulic servo system $[14,22,32]$ can be described as

$$
\frac{d y}{d t}=\frac{1}{T_{y}}\left(-k_{p} \omega-\frac{k_{i}}{\omega_{0}} \delta-k_{d} i \quad\right),
$$

where $k_{p}, k_{i}$ and $k_{d}$ represent the proportional, integral and differential adjustment coefficient, respectively. $T_{y}$ is the engager relay time constant.

\subsection{Dynamic expressions of transfer coefficients of the hydro-turbine}

Both the units under study are assumed to run with $80 \%$ load at the beginning of the transient process. Unit 1 is assumed subject to a sudden load decrease transient for $t=0 \mathrm{~s}$, while unit 2 operates normally. Moreover, to obtain the dynamic transfer coefficients of the hydro-turbine of the MUHS, the internal characteristics method [12] is utilized.

In light of this, the steady state equations of the Francis hydro-turbine [12] can be written as

$$
\left\{\begin{array}{l}
Q=\frac{W r^{2}+\frac{9.8 \eta H}{W}}{\frac{\operatorname{ctg} \alpha}{2 \pi b_{t}}+r \frac{\operatorname{ctg} \beta}{F}} \\
M_{t}=Q\left[\left(\frac{\operatorname{ctg} \alpha}{2 \pi b_{t}}+r \frac{\operatorname{ctg} \beta}{F}\right) Q-W r^{2}\right]
\end{array},\right.
$$

where $W, \alpha, b_{t}, F, r$ and $\beta$ are the generator rotor speed, the guide vane discharge angle, the height of the guide vane, the runner outlet area, the runner intermediate flow surface radius and the runner intermediate flow surface angle respectively. 
Standardizing Eq. (12), the internal characteristic equations for the transfer coefficients of the hydro-turbine can be expressed as

$$
\left\{\begin{array}{l}
e_{q y}=\frac{a}{1+a-c} \cdot \frac{q_{0}^{2} \csc ^{2} \alpha_{0}}{\omega_{0}} \cdot \frac{Y_{r} Q_{r}}{2 \pi b_{t} r^{2} k_{0} W_{r}} \\
e_{q w}=\frac{a-1}{1+a-c} \cdot \frac{q_{0}}{\omega_{0}} \\
e_{q h}=\frac{1}{1+a-c} \cdot \frac{q_{0}}{h_{0}} \\
e_{m y}=b e_{q y} \\
e_{m w}=b e_{q w}-\frac{m_{t 0}}{\omega_{0}} \\
e_{m h}=b e_{q h}+\frac{m_{t 0}}{h_{0}}
\end{array},\right.
$$

where $a=\frac{\omega_{0}^{2}}{\eta_{0} h_{0}} \cdot \frac{r^{2} \omega_{R}^{2}}{9.81 H_{R}}, \quad b=\left(1+c / Q_{0}\right) \frac{m_{t 0}}{q_{0}}, \quad c=\frac{2 q_{0}\left(q_{0}-q_{*}\right) Q_{R}^{2}}{2 d \eta_{0}-\left(q_{0}-q_{*}\right)^{2} Q_{R}^{2}}, \quad r=0.353 D_{1}, \quad k_{0}=\left(\frac{d y}{d \alpha}\right)_{0}$, $q_{0}=\frac{Q_{0}}{Q_{r}}, h_{0}=\frac{H_{0}}{H_{r}}, m_{t 0}=\frac{M_{t 0}}{M_{t r}}, \omega_{0}=\frac{W_{0}}{W_{r}} . d$ and $D_{1}$ refer respectively to the constant of flow passage component and the runner diameter of the hydro-turbine. Subscript * denotes the optimum operating situation.

The relation curves between the transfer coefficient and the power of the hydro-turbine (HL240-LJ-140), shown in Fig. 3, are calculated on the basis of the internal characteristics method [32].

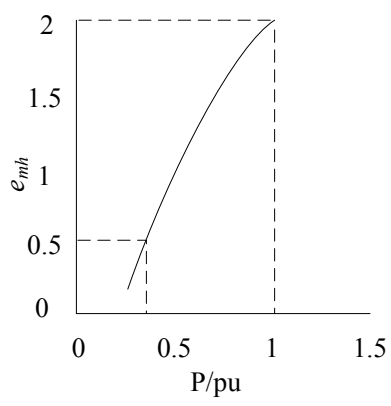

(a)

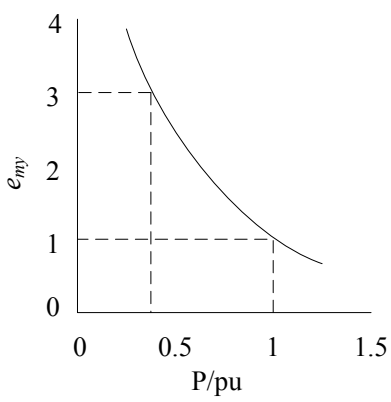

(b)

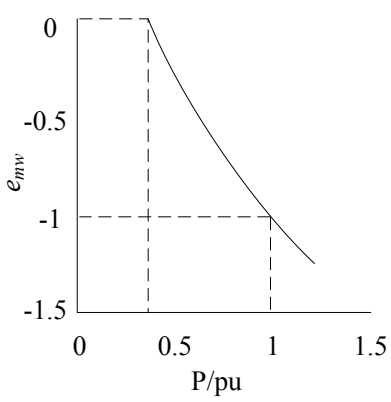

(c) 


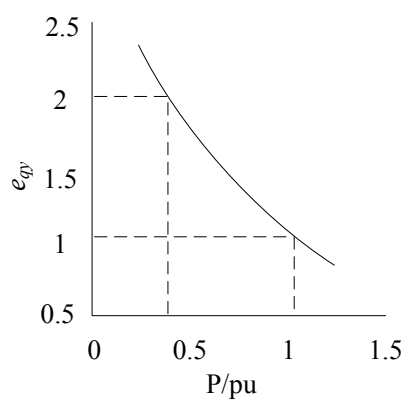

$(d)$

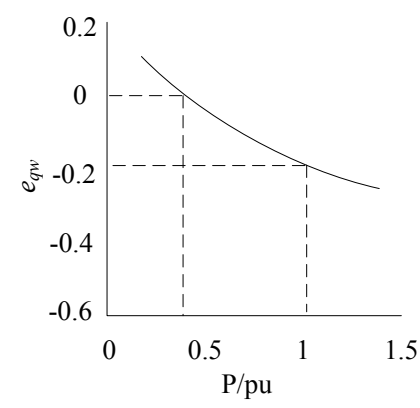

$(e)$

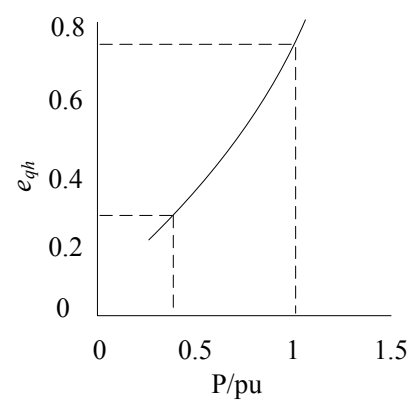

$(f)$

Fig. 3. Relation curves between the transfer coefficient and the power of the hydro-turbine

(HL240-LJ-140).

In this paper, the two-segment closing law for unit 1 is determined because of its universal applicability in hydropower stations. Also, in light of the literatures [12, 19, 32], we set the closing time of the guide vane for unit 1 to 5 s during the sudden load decrease transient, which is shown in Fig. 4.

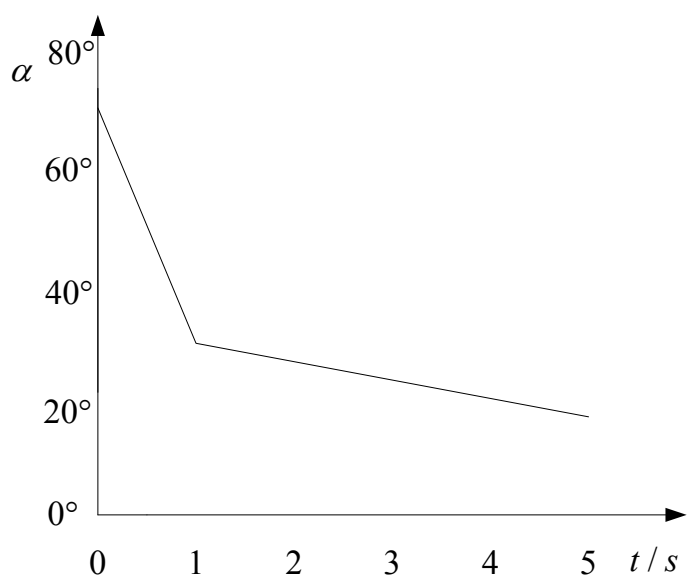

Fig. 4. Closing law of the guide vane for unit 1 in the sudden load decrease transient.

In light of the previous considerations, since the transfer coefficients of the hydro-turbine for unit 1 vary along with the operational conditions of the MUHS, six nonlinear dynamic transfer coefficients of the hydro-turbine, i.e. 


$$
\left\{\begin{array}{l}
e_{m y 1}=\frac{1}{5} \cos 4 \pi t-\frac{12}{5} e^{-t}+\frac{37}{10} \\
e_{m w 1}=\frac{1}{10} \cos 4 \pi t-\frac{11}{10} e^{-t}+\frac{3}{10} \\
e_{m h 1}=\frac{4}{25} \cos 4 \pi t+\frac{7}{5} e^{-t}+\frac{3}{20} \\
e_{q y 1}=\frac{2}{25} \sin 4 \pi t-\frac{4}{5} e^{-t}+\frac{11}{5} \\
e_{q w 1}=\frac{1}{50} \sin 4 \pi t-\frac{21}{100} e^{-t}+\frac{7}{100} \\
e_{q h 1}=\frac{1}{25} \sin 4 \pi t+\frac{23}{60} e^{-t}+\frac{1}{5}
\end{array} .\right.
$$

From Refs $[17-19,32,37]$, the impact of the fluctuation of unit 1 on unit 2 is limited, and unit 2 can be defined as a linear model. Thus, the fluctuation range of the load of the unit 2 can be supposed to be $\pm 20 \%$ in light of literatures [20-21,37]. As a consequence, the fluctuation range of the transfer coefficients of the hydro-turbine for unit 2 can be determined based on Fig. 3. More specifically, its fluctuation law cannot be predicted in advance. Therefore, the transfer coefficients of the hydro-turbine for unit 2 can be assumed to change randomly with time $t$. Then, on the basis of the fluctuation range observed in Fig. 3, six groups of stochastic transfer coefficients are generated for the hydro-turbine of unit 2. Finally, the six stochastic transfer coefficients of the hydro-turbine for the unit 2 can be obtained adopting the least-square method to perform five different polynomial fittings. The six stochastic transfer coefficients of the hydro-turbine for the unit 2 can be obtained. The results are shown in Eq. (15).

$$
\left[\begin{array}{c}
e_{m y 2} \\
e_{m w 2} \\
e_{m h 2} \\
e_{q y 2} \\
e_{q w 2} \\
e_{q h 2}
\end{array}\right]=\left[\begin{array}{cccccc}
-0.0354 & 0.4080 & -1.5562 & 2.0064 & 0 & 0.8797 \\
-0.0026 & 0.0185 & -0.0121 & -0.0875 & 0 & -0.6033 \\
0.0212 & -0.2462 & 0.9250 & -1.1195 & 0 & 1.8812 \\
0.0164 & -0.1944 & 0.7613 & -1.0039 & 0 & 1.5736 \\
0.0048 & -0.0556 & 0.2145 & -0.2817 & 0 & -0.0493 \\
-0.0040 & 0.0353 & -0.0858 & 0.0412 & 0 & 0.5796
\end{array}\right] .
$$




\subsection{MUHS model}

From the above analysis, we acquire the mathematical model of the MUHS is obtained as

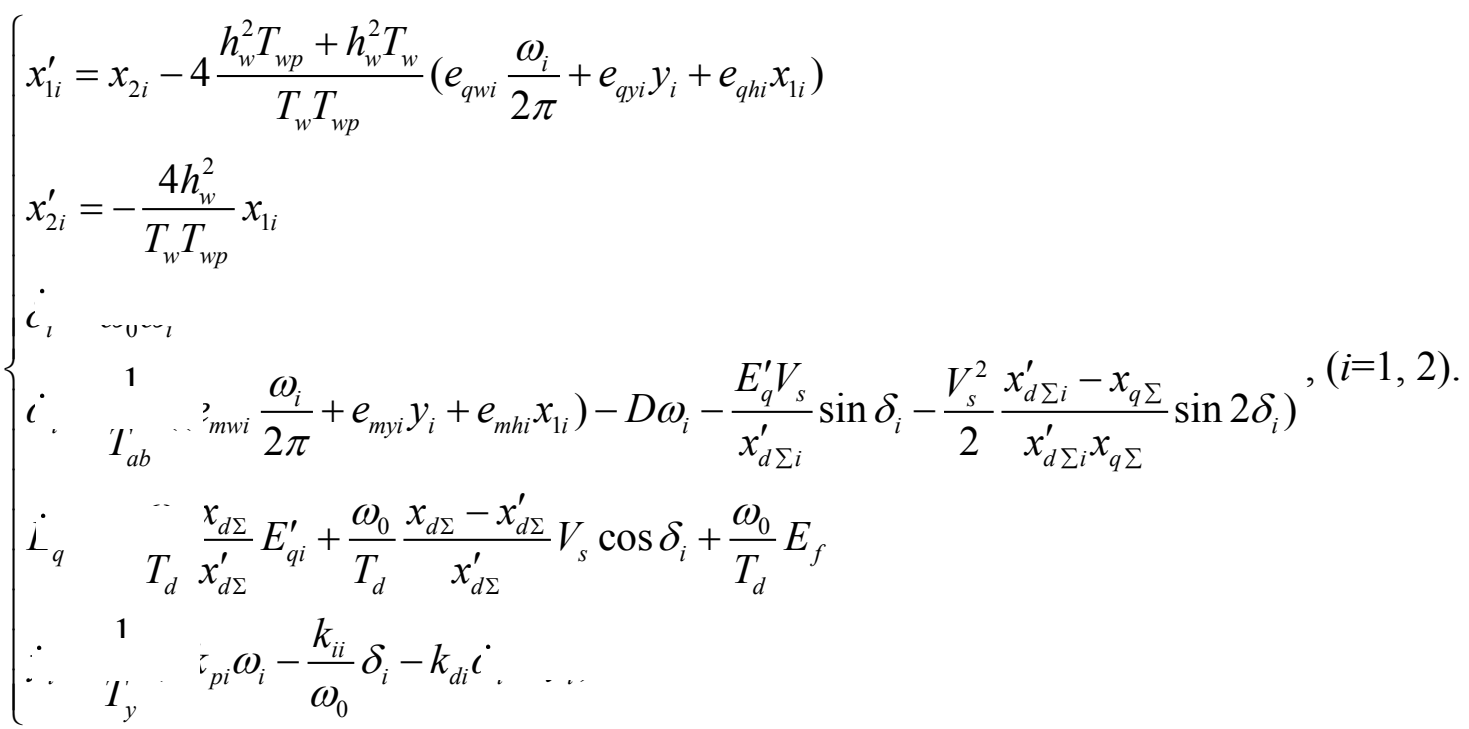

\section{Numerical experiments}

In this section, the Runge-Kutta method [35-36] is adopted to carry out a numerical application of the proposed model. The iteration step is 2000 and the initial values are $(0.001,0,0,0$, $0)$.

The basic parameters of the MUHS have been deduced from previous studies (see refs. [2, 17, 18-22]) and are shown in Table 2.

Table 2. Basic parameters of the MUHS

\begin{tabular}{|c|c|c|c|c|c|c|c|c|c|}
\hline Parameters & $T_{w p}$ & $\omega_{0}$ & $D$ & $E_{q}^{\prime}$ & $x_{q \Sigma}^{\prime}$ & $V_{s}$ & $T_{y}$ & $T_{w}$ & $h_{w}$ \\
\hline Values & 2 & 314 & 0.5 & 1.35 & 2 & 0.8 & 0.1 & 1 & 1 \\
\hline Parameters & $T_{a b}$ & $x_{d \Sigma 1}^{\prime}$ & $x_{d \Sigma 2}^{\prime}$ & $k_{P 1}$ & $k_{i 1}$ & $k_{d 1}$ & $k_{P 2}$ & $k_{i 2}$ & $k_{d 2}$ \\
\hline Values & 8 & 3 & 4 & 10 & 2 & 6 & 10 & 5 & 0.6 \\
\hline
\end{tabular}

Similarly, the bifurcation diagrams of the MUHS including unit 1and unit 2 are shown in Figs.

$5-6$. 


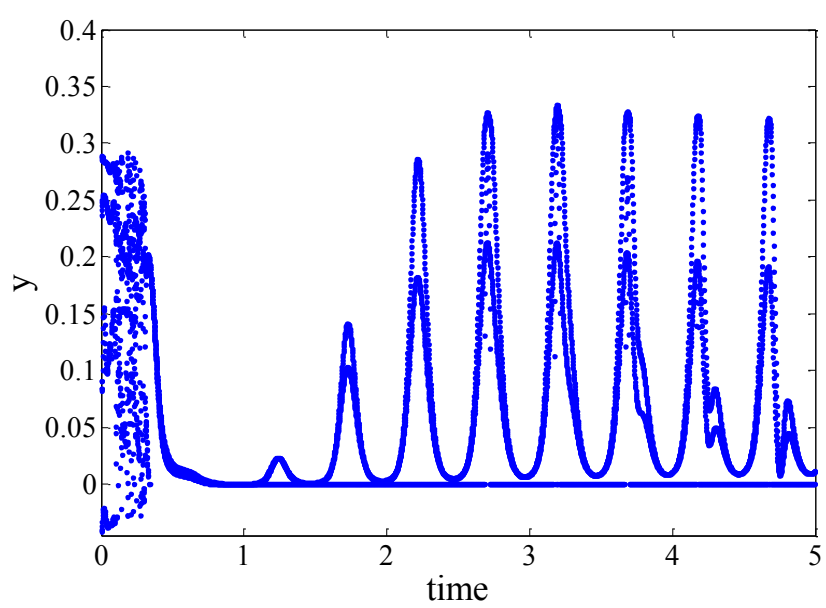

(a) $y-t$

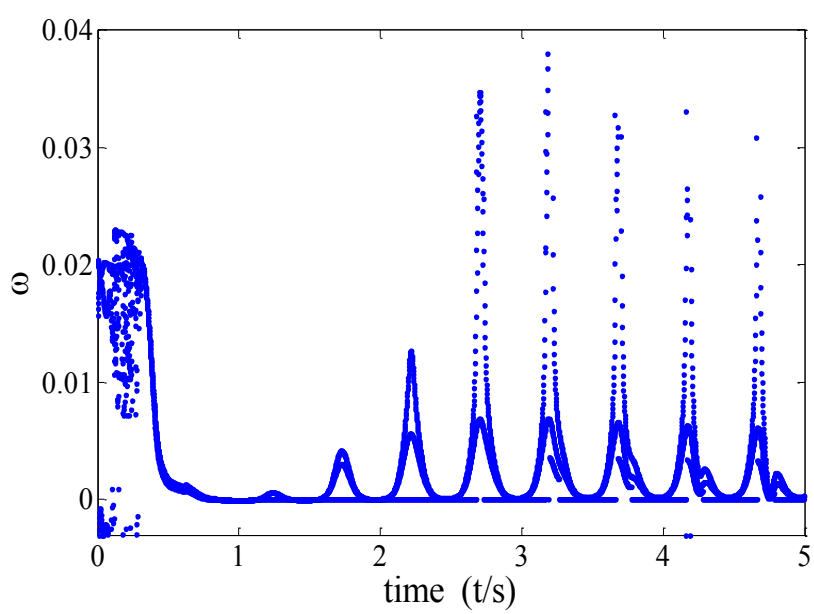

(b) $\omega-t$

Fig. 5. Bifurcation diagrams of unit 1 with time $t$.

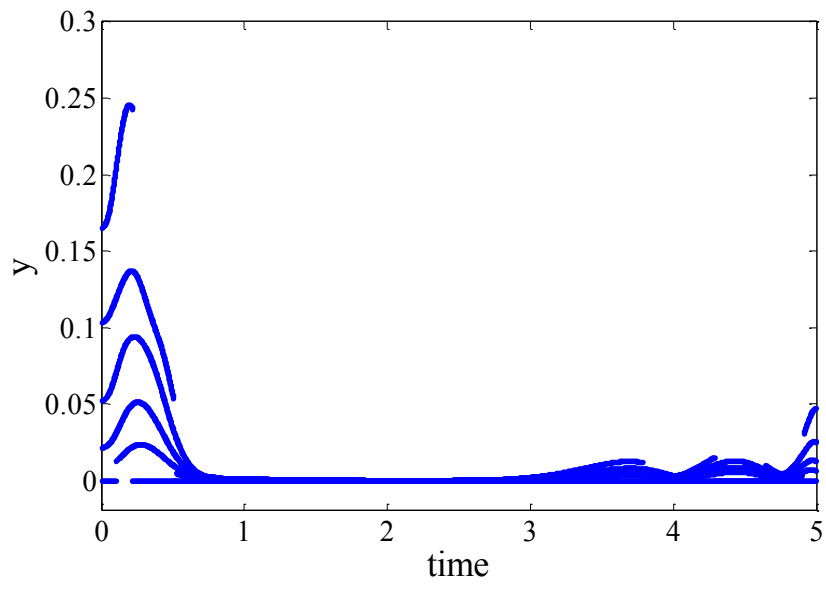

(a) $y-t$

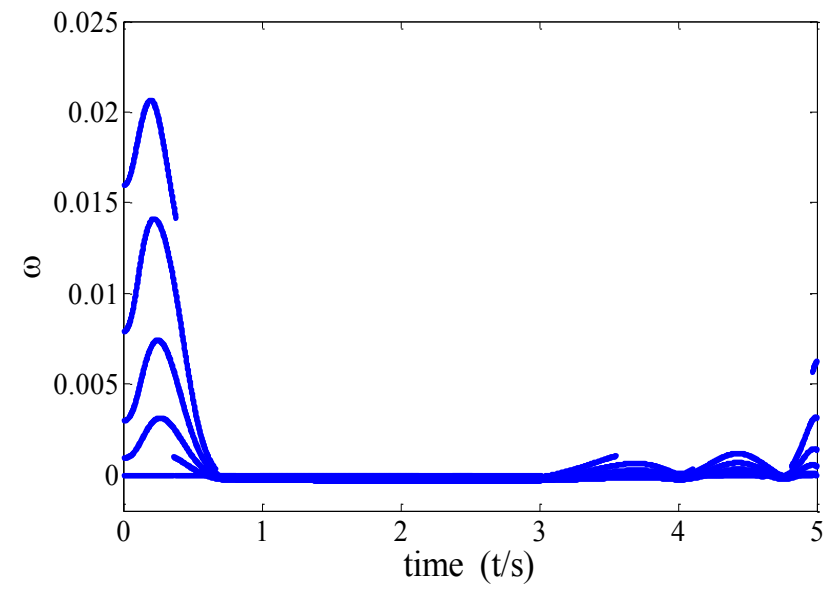

(b) $\omega-t$

Fig. 6. Bifurcation diagrams of unit 2 with time $t$.

As shown in Fig. 5, for $0 \leq t<0.35 \mathrm{~s}$, both the guide vane opening $(y)$ and the generator speed $(\omega)$ of unit 1 show chaotic deviation. The maximum deviation of the guide vane opening and the generator speed of unit 1 reach values of 0.3 and 0.23 respectively. This means that, due to the sudden decreasing of the load of unit 1, the guide vane opening rapidly increases and the generator speed also grows slightly. For $0.35 \leq t<1.62 \mathrm{~s}$, both deviations $y$ and $\omega$ of unit 1 decrease rapidly about zero, meaning that unit 1 operates safely under the control of the PID governor. When $1.62 \leq t \leq 5 \mathrm{~s}$, both $y$ and $\omega$ of unit 1 show significant fluctuations. This indicates that the 
sudden decrease of the load of unit 1 inevitably deteriorates the stability of the same unit.

As Fig. 6 shows, the larger numerical fluctuations of $y$ and $\omega$ occur for values of time $0 \leq t \leq 1.43 \mathrm{~s}$ compared with the time range of $1.43<t \leq 5 \mathrm{~s}$. The maximum deviations of the guide vane opening and the generator speed of unit 2 result respectively equal to 0.2455 and 0.2088 for $0 \leq t \leq 1.43 \mathrm{~s}$. When $1.43 \leq t \leq 2.5 \mathrm{~s}$, the deviations $y$ and $\omega$ for unit 2 fluctuate in their stable ranges. Finally, for $2.5 \leq t \leq 5 \mathrm{~s}$, slight numerical fluctuations occur. In other words, regarding the common penstock of the MUHS, its total flow remains constant for values of $t$ between $0 \mathrm{~s}$ and $5 \mathrm{~s}$. However, due to the decreasing of the hydro-turbine flow and the guide vane opening of unit 1 , the water pressure of unit 1 and the hydro-turbine flow of unit 2 increase. Therefore, significant fluctuations for the parameters of unit 2 can be observed. Obviously, the fluctuations threaten the stability of unit 2 . Nevertheless, it must be noted that, since the unit 2 is connected to the electric system, its frequency will eventually mach the frequency of the electric system.

Figs. 5-6 show that the deviations $y$ and $\omega$ of unit 1 result both larger than that of unit 2 . This is due to the larger intensity of the load disturbance for unit 1 in comparison to that of unit 2 . Moreover, the deviations $y$ of both units result higher than the corresponding deviations $\omega$. This indicates that, in order to guarantee the safety and stability of the electric system, large frequency fluctuations for the MUHS must be avoided under the control of the PID. Conversely, when adapting to the significant change of the hydro-turbine flow of unit 1 , a large deviation for the guide vane opening of the MUHS is registered.

Moreover, six time values for unit $1(t=0 \mathrm{~s}, t=0.35 \mathrm{~s}, t=0.7 \mathrm{~s}, t=1.62 \mathrm{~s}, t=1.73 \mathrm{~s}, t=2 \mathrm{~s})$ and five for unit $2(t=0 \mathrm{~s}, t=1.43 \mathrm{~s}, t=1.8 \mathrm{~s}, t=4.76 \mathrm{~s}, t=5 \mathrm{~s})$ are selected in order to further study the dynamic characteristics of the MUHS, as shown in Figs. 7-8. 


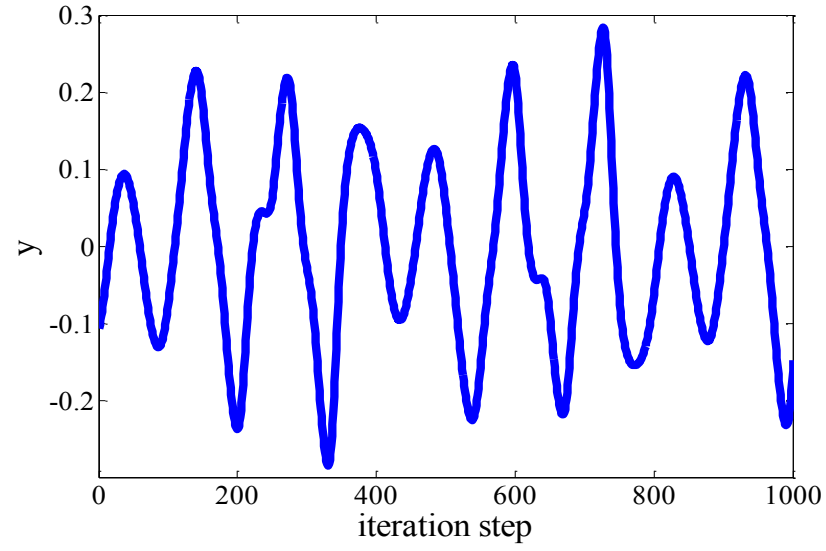

(al) $y-t$ at $t=0 \mathrm{~s}$

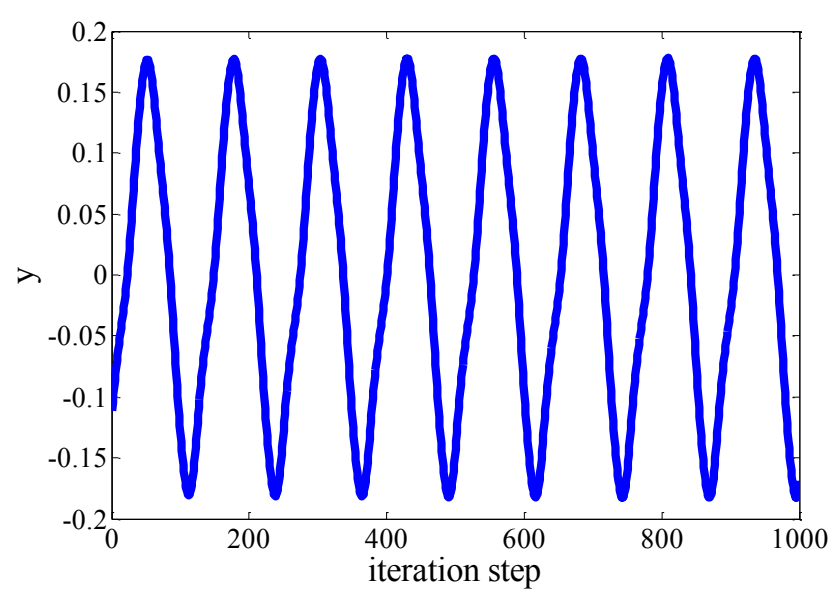

(b1) $y-t$ at $t=0.35 \mathrm{~s}$

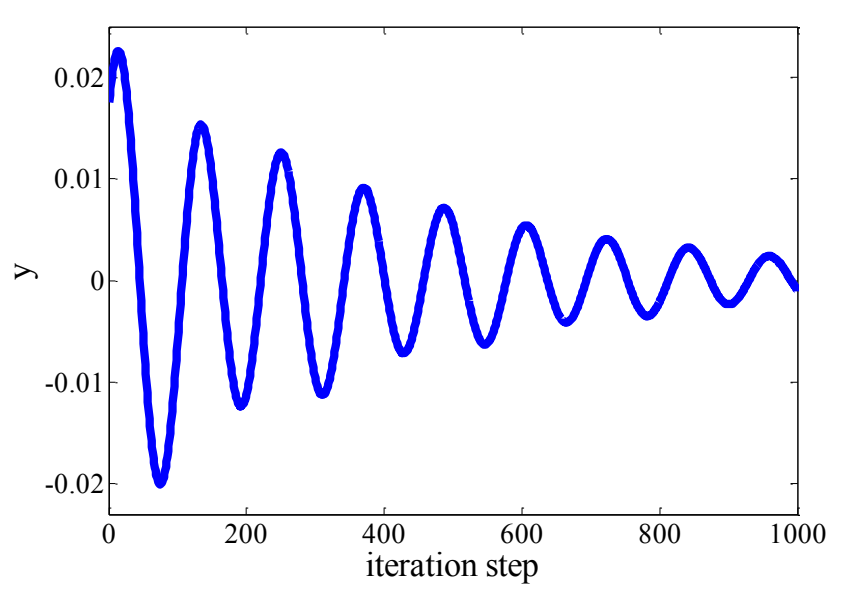

(c1) $y-t$ at $t=0.7 \mathrm{~s}$

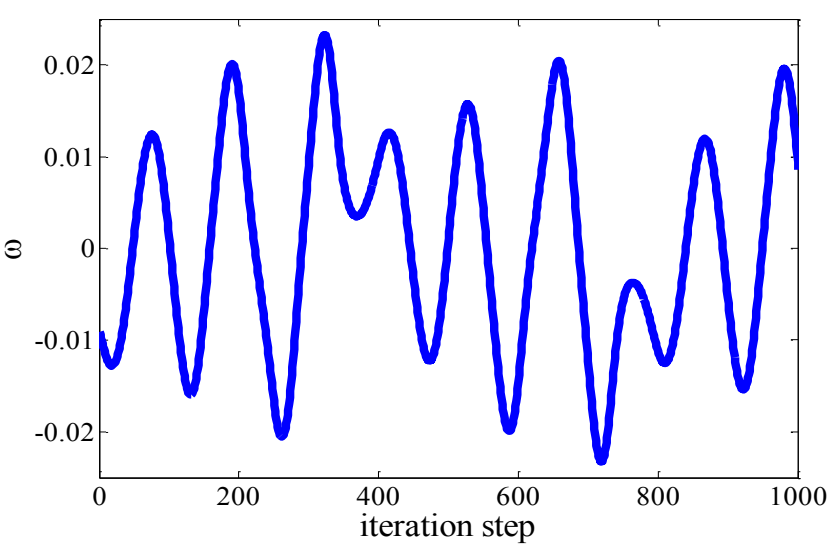

(a2) $\omega-t$ at $t=0 \mathrm{~s}$

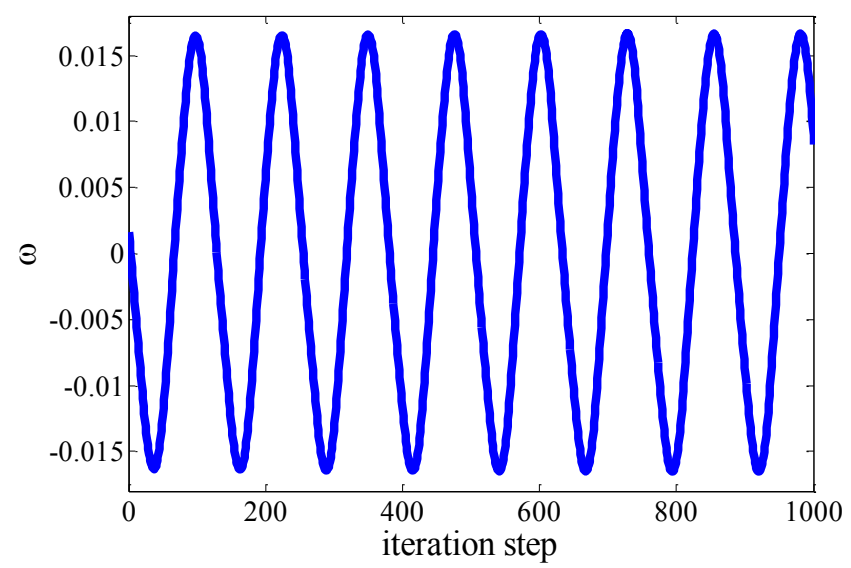

(b2) $\omega-t$ at $t=0.35 \mathrm{~s}$

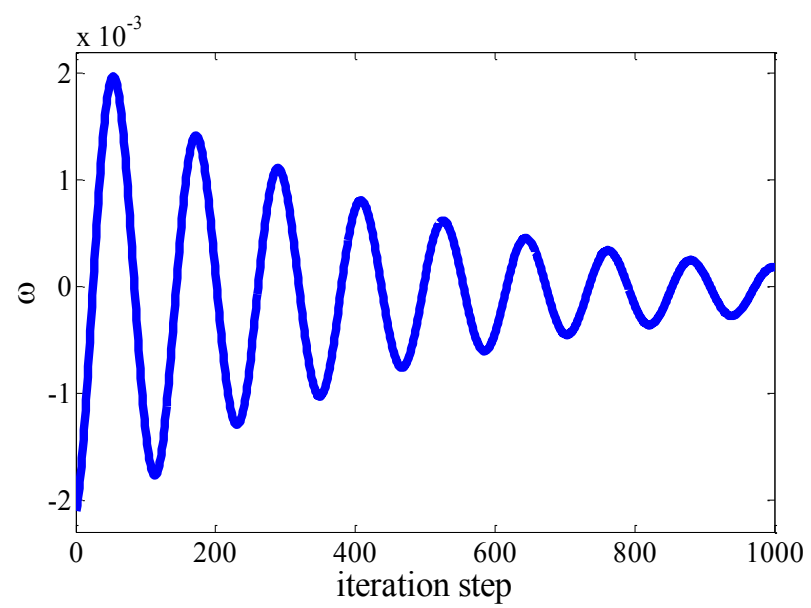

(c2) $\omega-t$ at $t=0.7 \mathrm{~s}$ 


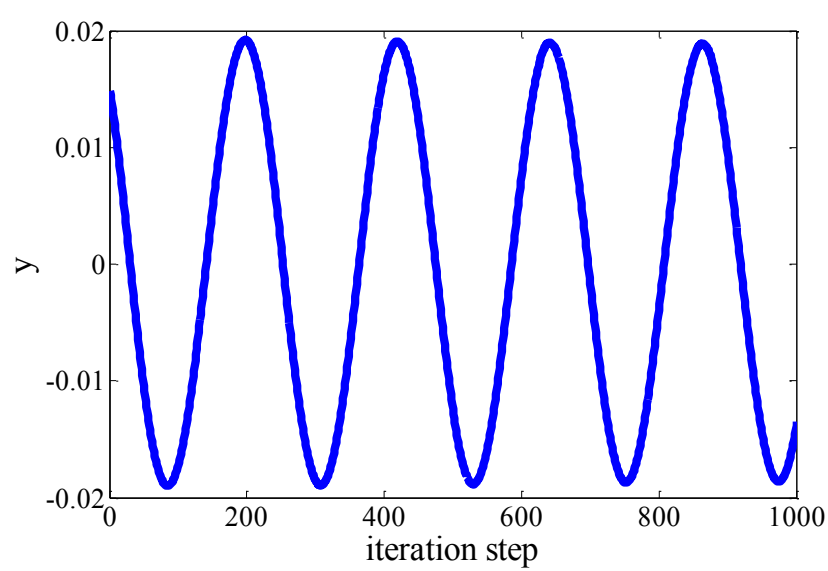

(d1) $y-t$ at $t=1.62 \mathrm{~s}$

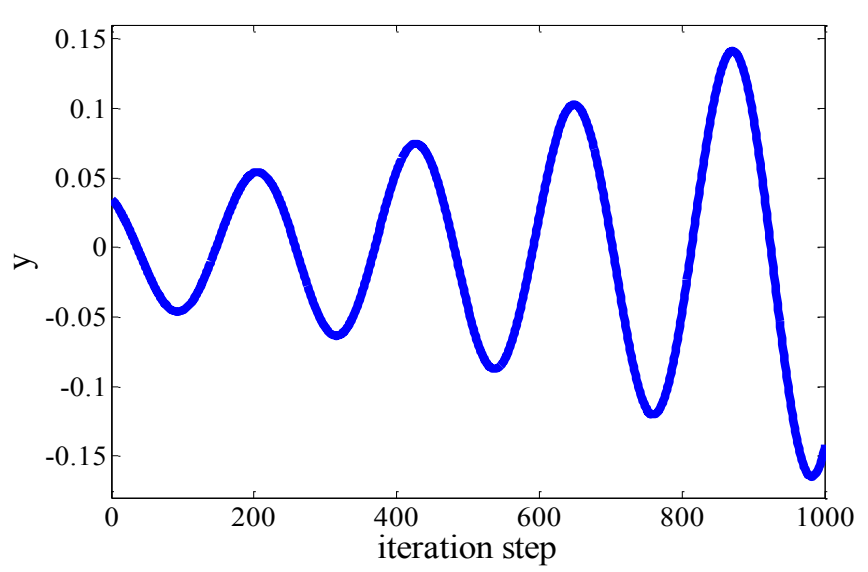

(e1) $y-t$ at $t=1.73 \mathrm{~s}$

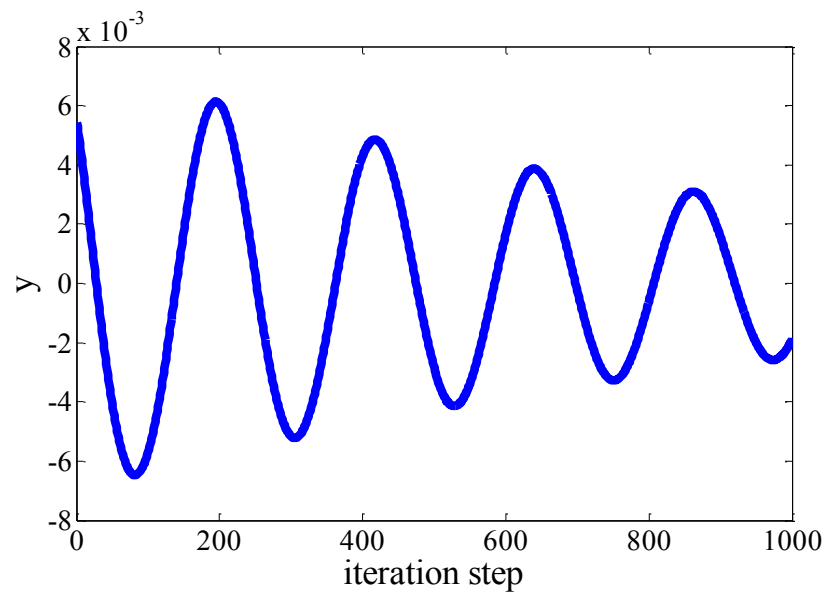

(f1) $y-t$ at $t=2 \mathrm{~s}$

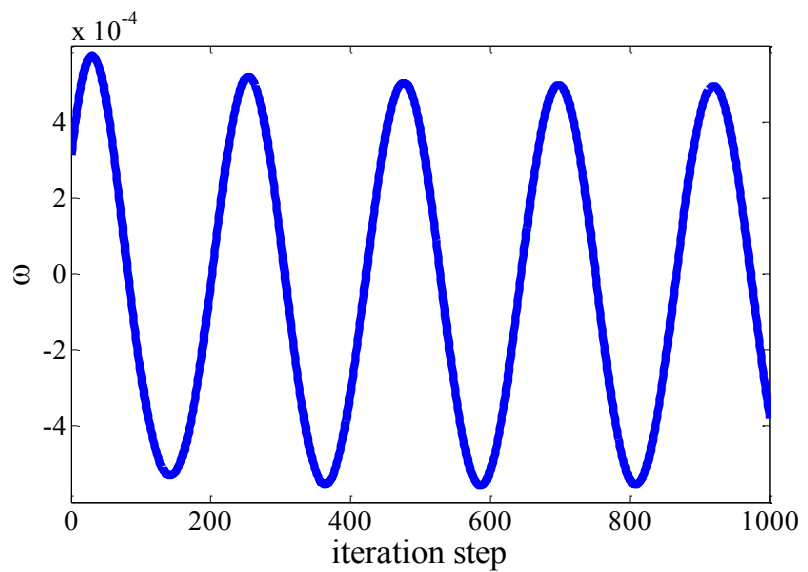

(d2) $\omega-t$ at $t=1.62 \mathrm{~s}$

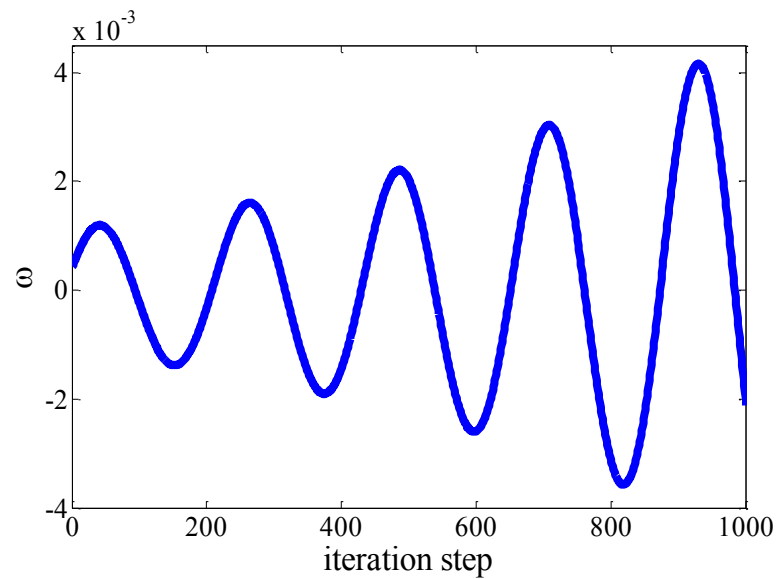

(e2) $\omega-t$ at $t=1.73 \mathrm{~s}$

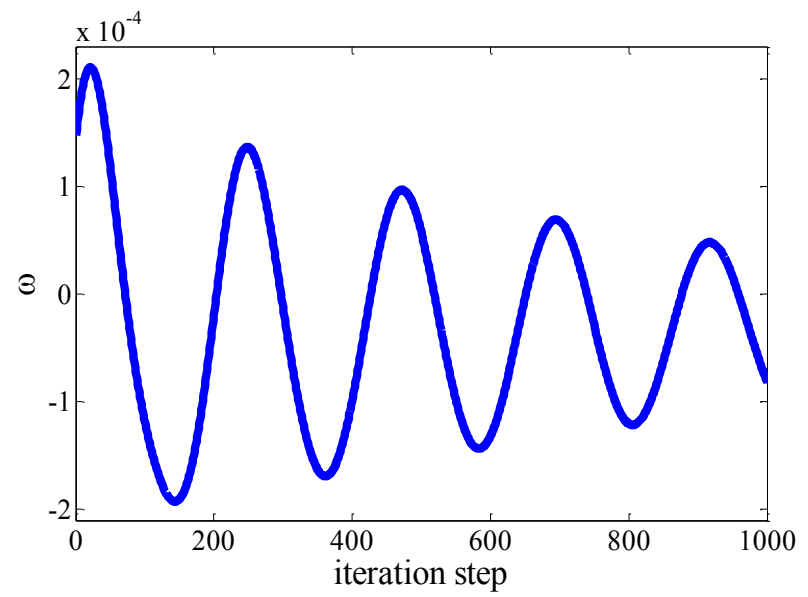

(f2) $\omega-t$ at $t=2 \mathrm{~s}$

Fig. 7. Time waveforms of unit 1 with different times. 


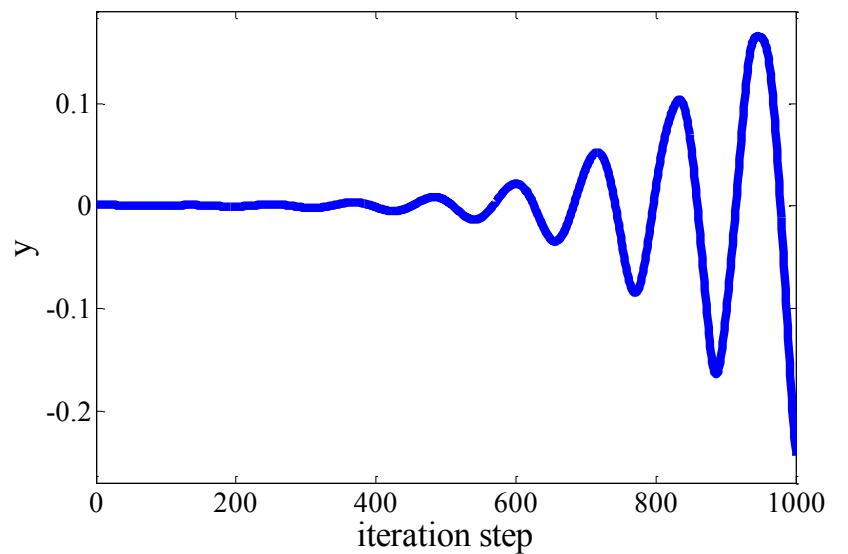

(al) $y-t$ at $t=0 \mathrm{~s}$

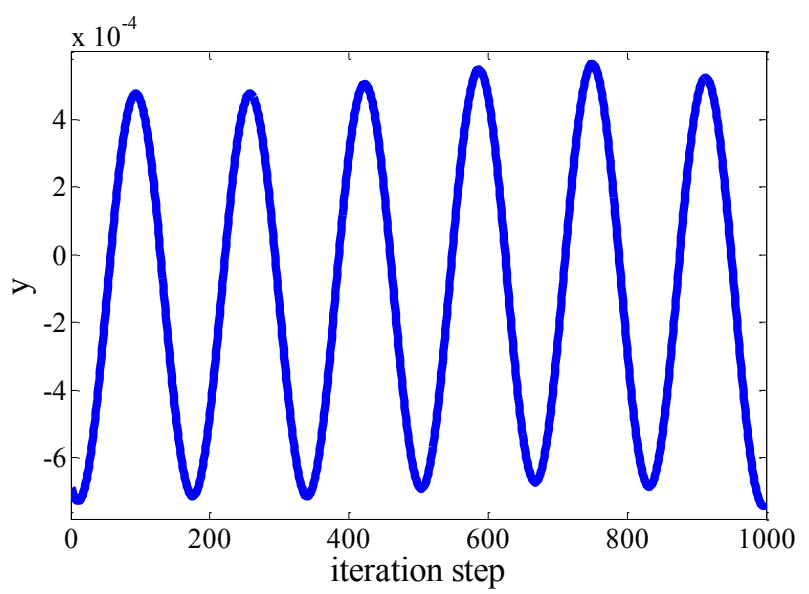

(b1) $y-t$ at $t=1.43 \mathrm{~s}$

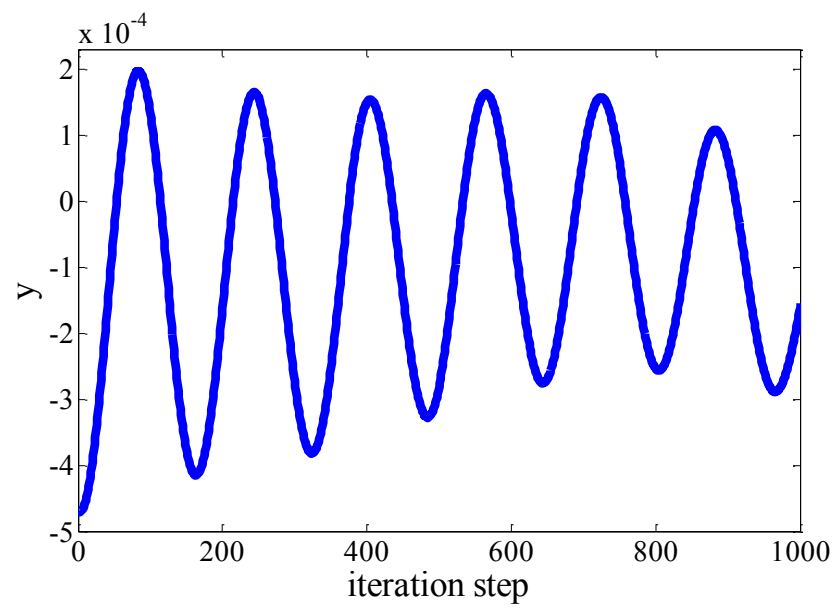

(cl) $y-t$ at $t=1.8 \mathrm{~s}$

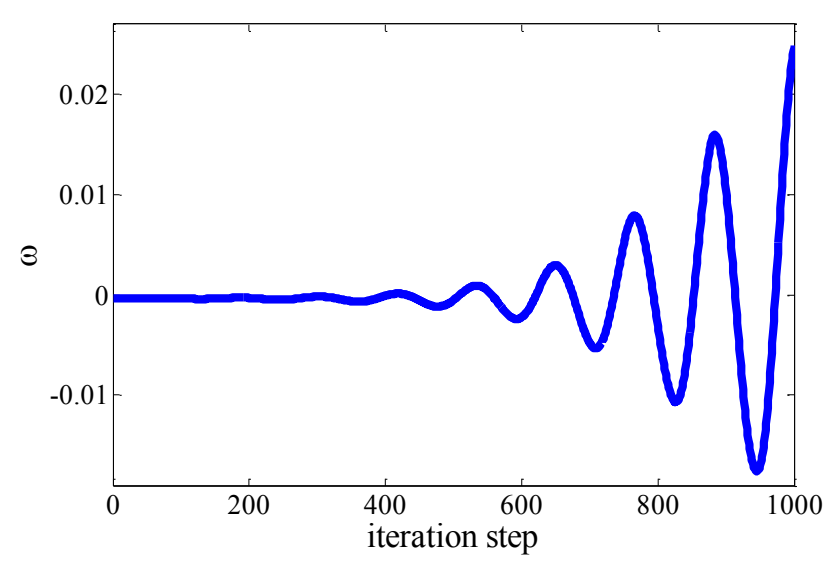

(a2) $\omega-t$ at $t=0 \mathrm{~s}$

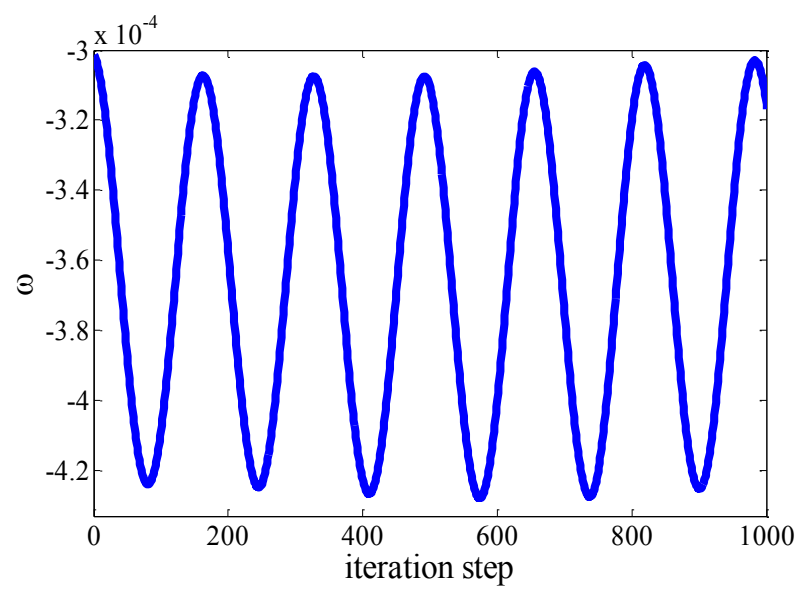

(b2) $\omega-t$ at $t=1.43 \mathrm{~s}$

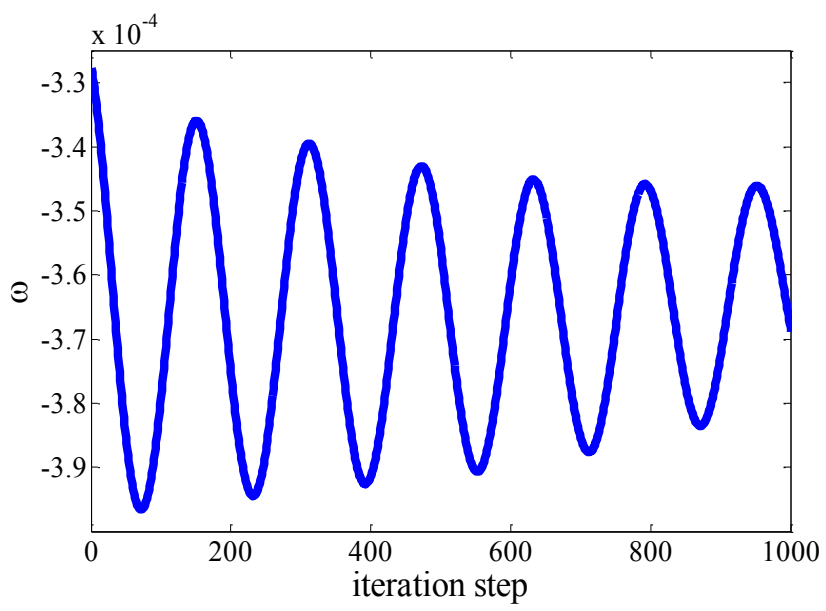

(c2) $\omega-t$ at $t=1.8 \mathrm{~s}$ 


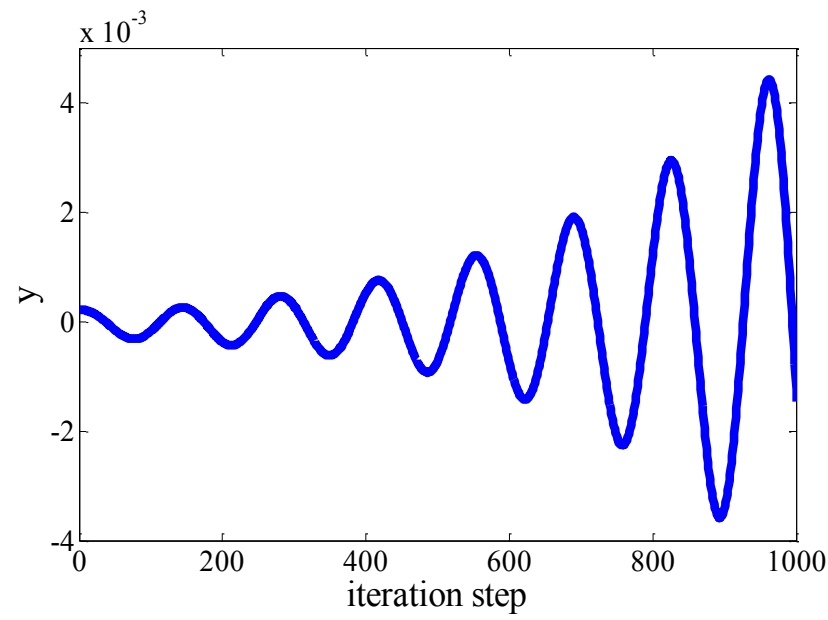

(d1) $y-t$ at $t=4.76 \mathrm{~s}$

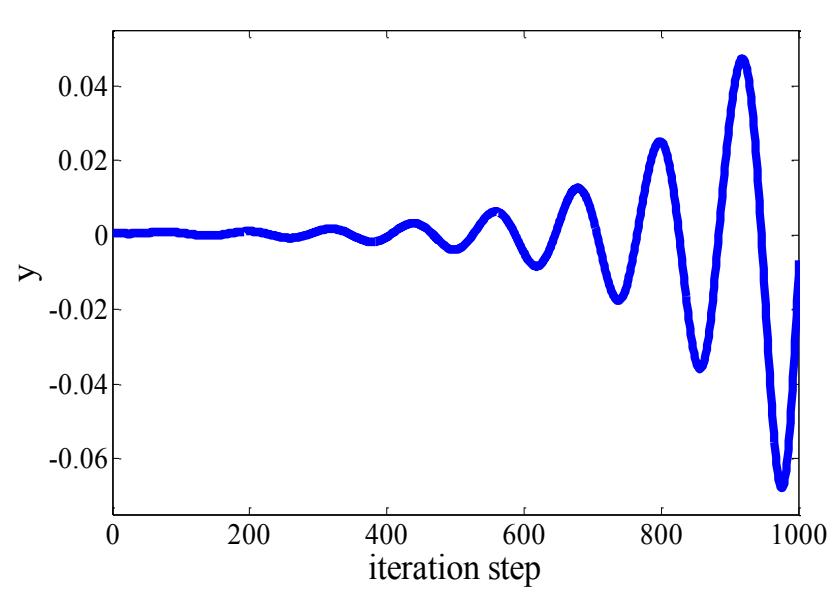

(e1) $y-t$ at $t=5 \mathrm{~s}$

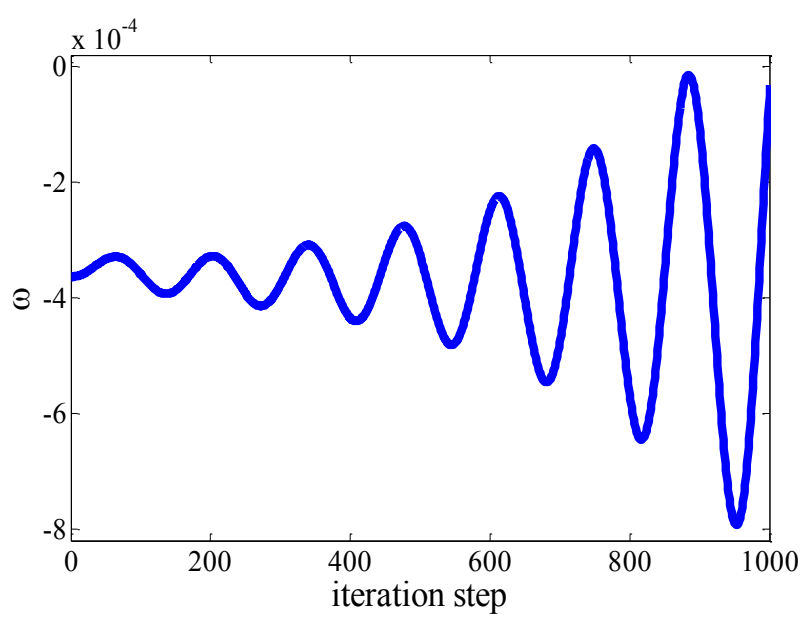

(d2) $\omega-t$ at $t=4.76 \mathrm{~s}$

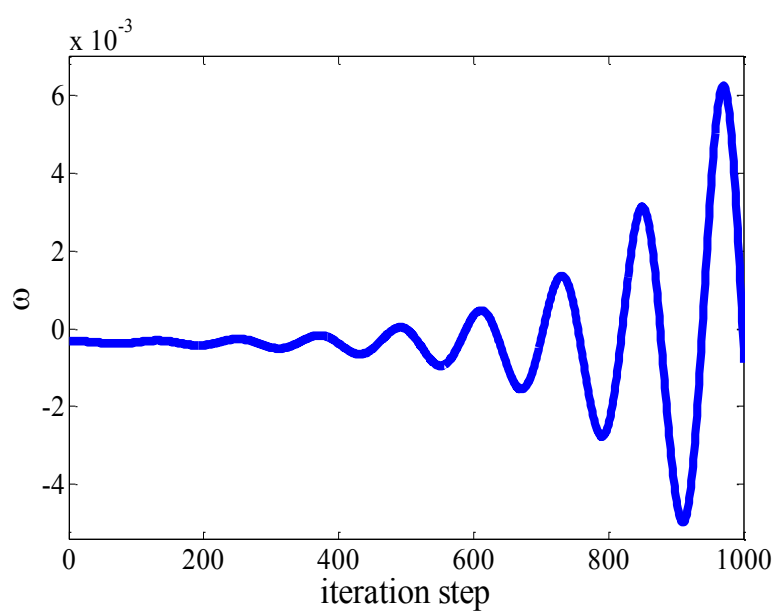

(e2) $\omega-t$ at $t=5 \mathrm{~s}$

Fig. 8. Time waveforms of unit 2 at different times.

As it is clearly shown in Figs. $7(a 1),(a 2),(b 1),(b 2),(c 1)$ and $(c 2)$, both the guide vane opening and the generator speed of unit 1 enter into a chaotic state at $t=0 \mathrm{~s}$. This means that unit 1 engenders conspicuous vibrations. The dynamic response of this unit results in a critical state for $t=0.35 \mathrm{~s}$. Conversely, the motion regularities of the guide vane opening and the generator speed of unit 1 converge at $t=0.7 \mathrm{~s}$. The above results reveal that unit 1 evolves from an unstable state to a stable state.

As Figs. $7(d 1),(d 2),(e 1),(e 2),(f 1)$ and $(f 2)$ show, the motion regularities of the guide vane opening and the generator speed of unit 1 result periodical at $t=1.62 \mathrm{~s}$. Both the guide vane opening 
and the generator speed of unit 1 make diverging motions at $t=1.73 \mathrm{~s}$, while they converge at $t=2 \mathrm{~s}$. This implies that unit 1 enters into a state of intermittent vibration after $t=1.62 \mathrm{~s}$.

The dynamic trends of unit 2 are shown in Figs. 8(a1), (a2), (b1), (b2), (c1) and (c2). The dynamic responses of the guide vane opening and the generator speed of unit 2 diverge at $t=0 \mathrm{~s}$. On the contrary, they both make periodic motions at $t=1.43 \mathrm{~s}$. When $t=1.8 \mathrm{~s}$, they return to their original positions. This indicates that unit 2 completes the transition from instability to stability.

Figs. $8(d 1),(d 2),(e 1)$ and $(e 2)$ show that the motion regularities of the guide vane opening and the generator speed of unit 2 maintain a diverging state at $t=4.76 \mathrm{~s}$ and $t=5 \mathrm{~s}$, respectively. However, the difference is that the dynamic response of unit 2 is more obvious at $t=5 \mathrm{~s}$ compared with the time $t=4.76 \mathrm{~s}$. It means that the irregular vibration of the unit 2 appears.

\section{Comparisons}

The results obtained in this study, show that the novel mathematical model proposed for the MUHS can effectively capture the essence of the nonlinearity of the system during the transient process. In order to validate the model, a comparison between the novel and previous mathematical model of the MUHS has been performed.

The model provided by Ba DD et al. [38] has been taken into consideration and applied introducing the transfer coefficients [32] into the model of unit 1. Conversely, the transfer coefficients of the hydro-turbine of unit 2 [38] are assumed constants, and the basic system parameters are considered unchanged in this paper. Finally, the Runge-Kutta method is adopted to obtain the numerical results, as shown in Fig. 9. 


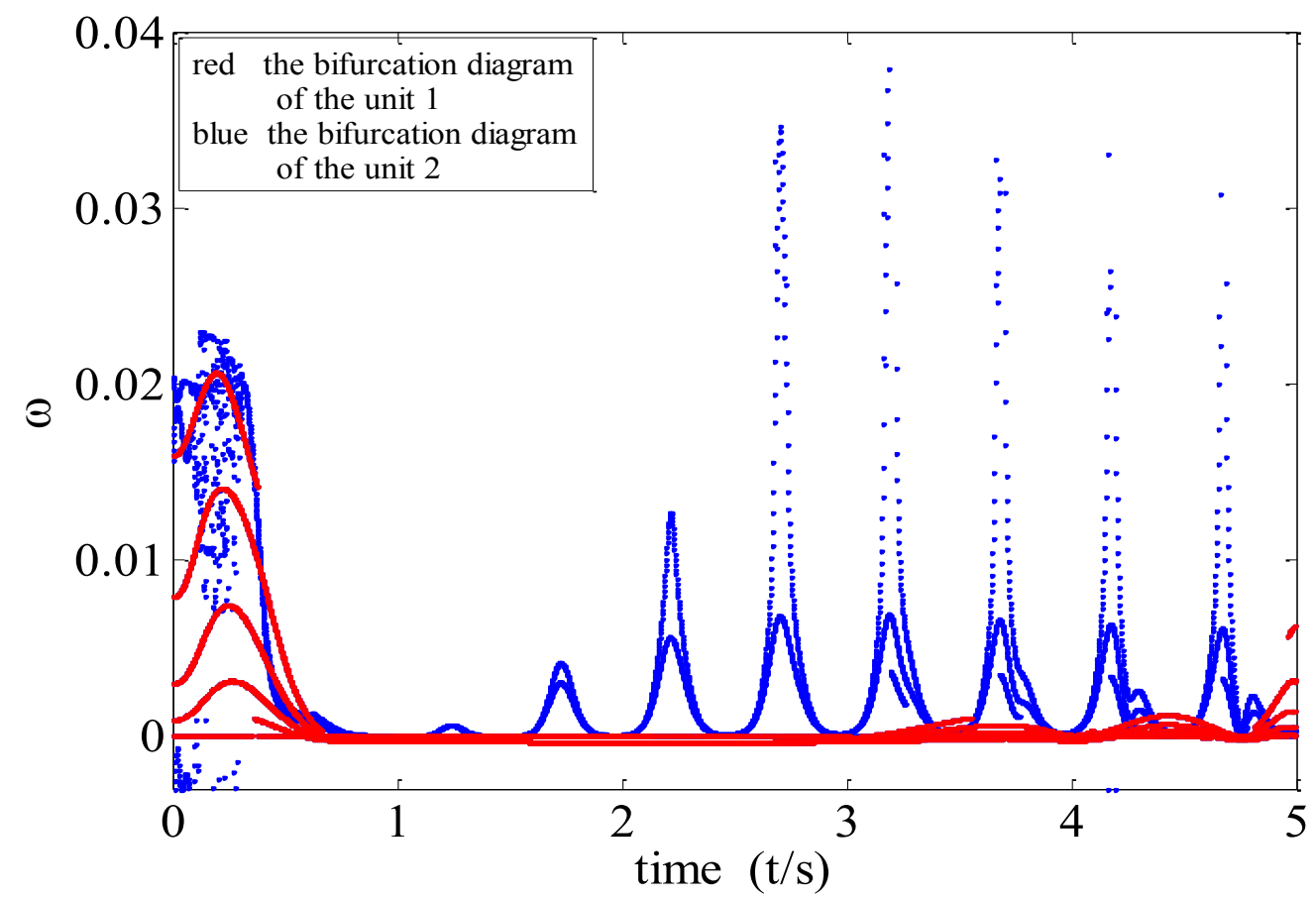

(a) Bifurcation diagram of the novel mathematical model

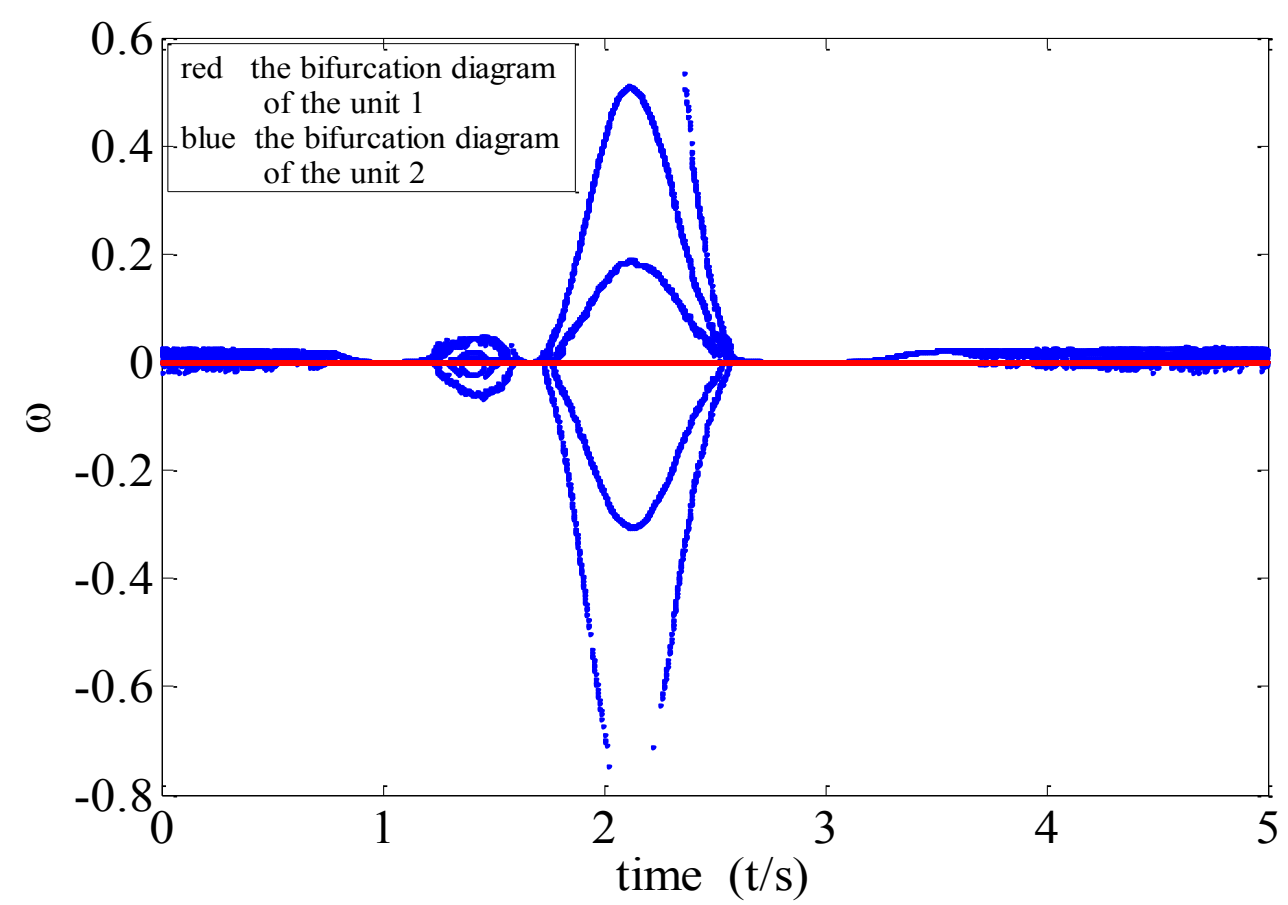

(b) Bifurcation diagram of the previous mathematical model

Fig. 9. Comparison of the bifurcation diagrams of the multi-unit hydropower system of the proposed and the one from ref. [38].

As shown in Fig. 9, the generator rotor speed of unit 2 fluctuates along with the generator rotor speed of unit 1 with regard to the proposed model. In addition, the variation range of the deviation of 
the generator rotor speed results larger than that of unit 2. Conversely, according to the results obtained for the model of $\mathrm{Ba} \mathrm{DD}$, the generator rotor speed for unit 1 enters into chaotic state when $0 \leq t \leq 0.8 \mathrm{~s}$ and $3.4 \leq t \leq 5 \mathrm{~s}$; fluctuations of the generator rotor speed are registered for $1.1 \leq t \leq 2.7 \mathrm{~s}$. When $0.8<t<1.1 \mathrm{~s}$ and $2.7<t<3.4 \mathrm{~s}$, the MUHS operates stably. In the case of the $\mathrm{Ba} \mathrm{DD}$ model for unit 2, the deviation of the generator rotor speed changes around zero for the whole transient process. This implies that the changes of the system parameters of unit 2 have no impact on unit 1 . Therefore, model the implemented by Ba DD cannot better describe the dynamic behavior of the MUHS. Moreover, the maximum deviation of the generator rotor speed of unit 1 according to the model proposed in this study is 0.03797 , while according to Ba DD model is 0.5348. However, the fact is that, the generator rotor speed cannot change dramatically in the transient state due to its connection with the electric system. Therefore, the novel mathematical model shows obvious advantages over the previously existent model.

\section{Conclusions}

In this work, the model of a MUHS with 2 operating units has been implemented. The computation of six stochastic transfer coefficients for the hydro-turbine of unit 2 is proposed on the basis of the constraints imposed on the fluctuation range of the same unit. Also, considering the changes of the operational conditions, the dynamic transfer coefficients of the hydro-turbine, assumed in sudden load decrease transient, are introduced into the model of unit 2 . In addition to this, a novel nonlinear dynamic mathematical model of the MUHS is proposed and the dynamic characteristics of the MUHS are investigated using bifurcation diagrams and time waveforms.

The results obtained from the numerical application of the methods proposed show that the fluctuation characteristics of unit 1 are closely related to those of unit 2 . The responses of both units experience three stages, namely the unstable stage, the stable stage and the critical stage. This 
indicates that the state of the MUHS evolves from stability to instability. Moreover, the intensity of the vibration of unit 1 is significantly larger than that of unit 2 . The reason of this can be explained by the states of the two units: while unit 1 is a transient state due to a sudden decrease of the load, unit 2 runs normally. It must be noted that the variation of the guide vane opening is larger than that of the generator speed. This is due to the frequency of the electric system that limits significantly the frequency variation of the MUHS. Finally, it is worth mentioning that the change of the hydro-turbine flow of unit 1 directly influences the hydro-turbine flow of the common penstock and unit 2. The analytical methods proposed and numerical results obtained in this study aim to provide theoretical guidance to the safe operation of the hydropower station.

\section{Discussion}

The approach proposed in this work provides guidance for actual operation of MUHSs. First of all, a model is established to adequately describe the nonlinearity of the MUHS and to study the stability of hydropower systems. This model is proven to ensure the safe and economical operation of hydropower stations. Second, the numerical results obtained are in good agreement with the corresponding theory and practical engineering, providing new ideas for the process monitoring and fault detection of hydropower plants. In addition to this, the model proposed in this study can be adopted for the design of the MUHS controller.

Therefore, future research will focus on the study of the controller of the MUHS during the transient process to enhance the operational stability of hydropower stations. Also, the fault diagnosis of the MUHS will be further investigated adopting the mentioned results in the transient process. 


\section{Acknowledgements}

This work was supported by the scientific research foundation of National Natural Science Foundation of

China--Outstanding Youth Foundation (51622906), National Natural Science Foundation of China (51479173),

Fundamental Research Funds for the Central Universities (201304030577), Scientific research funds of Northwest A\&F

University (2013BSJJ095), Science Fund for Excellent Young Scholars from Northwest A\&F University and Shaanxi

Nova program (2016KJXX-55).

\section{References}

[1] Pico H.V., McCalley J.D., Angel A., and et al.: Analysis of very low frequency oscillations in hydro-dominant power systems using multi-unit modeling. IEEE T. Power Syst. 27, 1906-1915 (2012). DOI: 10.1109/TPWRS.2012.2187805

[2] Wei S.P., 2011. Simulation of hydraulic turbine regulating system. Wuhan, Huazhong University of Science \& Technology Press [in Chinese]. ISBN: 9787560971483

[3] Guo W.C., Yang J.D., Wang M.J.: Nonlinear modeling and stability analysis of hydro-turbine governing system with sloping ceiling tailrace tunnel under load disturbance. Energy Conv. Manag. 106, 127-138 (2015). DOI: 10.1016/j.enconman.2015.09.026

[4] Pennacchi P., Chatterton S., Vania A.: Modeling of the dynamic response of a Francis turbine. Mech. Syst. Signal Proc. 29, 107-119 (2012). DOI: 10.1016/j.ymssp.2011.05.012

[5] Pennacchi P., Borghesani P., Chatterton S.: A cyclostationary multi-domain analysis of fluid instability in Kaplan turbines. Mech. Syst. Signal Pr. 60-61, 375-390 (2015). DOI: 10.1016/j.ymssp.2014.08.026

[6] Zeng Y., Zhang L.X., Guo Y.K., Qian J., Zhang C.L.: The generalized Hamiltonian model for the shafting transient analysis of the hydro turbine generating sets. Nonlinear Dyn. 76, 1921-1933 (2014). DOI: 10.1007/s11071-014-1257-9

[7] Jain S.V., Swarnkar A., Motwani K.H., and et al.: Effects of impeller diameter and rotational speed on performance of pump running in turbine mode. Energy Conv. Manag. 89, 808-824 (2015). DOI: $10.1016 /$ j.enconman.2014.10.036

[8] Kranjcic D., Stumberger G.: Differential Evolution-Based Identification of the Nonlinear Kaplan Turbine Model. IEEE T. Energy Conver. 29, 178-187 (2014). DOI: 10.1109/TEC.2013.2292927

[9] De Jaeger E., Janssens N., Malfliet B., and et al.: Hydro turbine model for system dynamic studies. IEEE Trans. Power Syst. 9, 1709-1715 (1994). DOI: 10.1109/59.331421

[10] Li Y.L., Xu D.L.: Chaotification of quasi-zero-stiffness system with time delay control. Nonlinear Dyn. 86, 353-368 (2016). DOI: 10.1007/s11071-016-2893-z

[11] Guido A.R., Adiletta G.: Dynamics of a rigid unbalanced rotor with nonlinear elastic restoring forces: Part I theoretical analysis. Nonlinear Dyn. 19, 359-385 (1999). DOI: 10.1023/A: 1008336006400

[12] Chang J.S., 2005. Transients of hydraulic machine installations. Beijing, Higher Education Press [in Chinese]. ISBN: 7040176475 
[13] IEEE Working Group.: Hydraulic-turbine and turbine control-models for system dynamic studies. IEEE Trans. Power Syst. 7, 167-79 (1992).

[14] Chen D.Y., Ding C., Ma X.Y., and et al.: Nonlinear dynamical analysis of hydro-turbine governing system with a surge tank. Appl. Math. Model 37, 7611-7623 (2013). DOI: 10.1016/j.apm.2013.01.047

[15] Zeng Y., Zhang L.X., Guo Y.K., and et al.: Hamiltonian Stabilization Additional L-2 Adaptive Control and Its Application to Hydro Turbine Generating Sets. International Journal of Control Automation and Systems 13, 867-876 (2015). DOI: 10.1007/s12555-013-0460-7

[16] Chen L.P., He Y.G., Chai Y., Wu R.C.: New results on stability and stabilization of a class of nonlinear fractional-order systems. Nonlinear Dyn. 75, 633-641 (2014). DOI: 10.1007/s11071-013-1091-5

[17] Shen Z.Y., 1991. The analysis of hydraulic turbine system. 1st ed. Beijing, Water Resources and Electric Power Press [in Chinese]. ISBN: 9787120014407

[18] Xu B.B., Chen D.Y., Zhang H., Zhou R.: Dynamic analysis and modeling of a novel fractional-order hydro-turbine-generator unit. Nonlinear Dyn. 81, 1263-1274 (2015). DOI: 10.1007/s11071-015-2066-5

[19] Shen Z.Y., 1998. Hydraulic turbine regulation. Beijing, China Water \& Power Press [in Chinese]. ISBN: 9787801244123

[20] Kishor N., Singh S.P., Raghuvanshi A.S.: Dynamic simulations of hydro turbine and its state estimation based LQ control. Energy Convers. Manage. 47, 3119-3137 (2006). DOI: 10.1016/j.enconman.2006.03.020

[21] Kishor N., Saini R.P., Singh S.P.: A review on hydropower plant models and control. Renew. Sust. Energ. Rev. 11, 776-796 (2007). DOI: 10.1016/j.rser.2005.06.003

[22] Chen D.Y., Ding C., Do Y.H., and et al.: Nonlinear dynamic analysis for a Francis hydro-turbine governing system and its control. J. Franklin. I. 351, 4596-4618 (2014). DOI: 10.1016/j.jfranklin.2014.07.002

[23] Teran L.A., Roa C.V., Munoz-Cubillos J., and et al.: Failure analysis of a run-of-the-river hydroelectric power plant. Eng. Fail. Anal. 68, 87-100 (2016). DOI: 10.1016/j.engfailanal.2016.05.035

[24] Pavesi G., Cavazzini G., Ardizzon G.: Numerical Analysis of the Transient Behaviour of a Variable Speed Pump-Turbine during a Pumping Power Reduction Scenario. Energies 9, (2016). DOI: 10.3390/en9070534

[25] Guo W.C., Yang J.D., Chen J.P., Wang M.J.: Nonlinear modeling and dynamic control of hydro-turbine governing system with upstream surge tank and sloping ceiling tailrace tunnel. Nonlinear Dyn. 84, 1383-1397 (2016). DOI: 10.1007/s11071-015-2577-0

[26] Trivedi C., Cervantes M.J., Gandhi B.K., Dahlhaug Q.G.: Transient pressure measurements on a high head model Francis turbine during emergency shutdown, total load rejection, and runaway. J. Fluids Eng. 136, (2014). DOI: 10.1115/1.4027794

[27] Trivedi C., Cervantes M.J., Gandhi B.K.: Investigation of a High Head Francis Turbine at Runaway Operating Conditions. Energies 9, (2016). DOI: 10.3390/en9030149

[28] Nuantong W., Taechajedcadarungsri S.: Optimal design of VLH axial hydro-turbine using regression analysis and multi-objective function (GA) optimization methods. J. Appl. Fluid. Mech. 9, 2291-2298 (2016).

[29] Shiva C.K., Mukherjee V.: Automatic Generation Control of Hydropower Systems Using a Novel Quasi-oppositional Harmony Search Algorithm. Electr. Pow. Compo. Sys. 44, 1478-1491 (2016). DOI: 10.1080/15325008.2016.1147103 
[30] Qian J., Zeng Y., Guo Y.K., Zhang L.X.: Reconstruction of the complete characteristics of the hydro turbine based on inner energy loss. Nonlinear Dyn. 86, 963-974 (2016). DOI: 10.1007/s11071-016-2937-4.

[31] Ardizzon G., Cavazzini G., Pavesi G.: A new generation of small hydro and pumped-hydro power plants: Advances and future challenges. Renew. Sust. Energ. R. 31, 746-761 (2014).

[32] Zhang H., Chen D.Y., Xu B.B., and et al.: Nonlinear modeling and dynamic analysis of hydro-turbine governing system in the process of load rejection transient. Energy Conv. Manag. 90, 128-137 (2015). DOI: 10.1016/j.enconman.2014.11.020

[33] Carapellucci R., Giordano, Pierguidi F.: Techno-economic evaluation of small-hydro power plants: Modelling and characterisation of the Abruzzo region in Italy. Renw. Energ. 75, 395-406 (2015). DOI: 10.1016/j.renene.2014.10.008

[34] Florides G., Kalogirou S.: Ground heat exchangers - A review of systems, models and applications. Renw. Energ. 32, 2461-2478 (2007). DOI: 10.1016/j.renene.2006.12.014

[35] Bank R.E., Coughran W.C., Fichtner W., and et al.: Transient simulation of silicon devices and circuits. IEEE T. Comput. Aid. D. 4, 436-451 (2006). DOI: 10.1109/TCAD.1985.1270142

[36] Shampine L.F., 1994. Numerical solution of ordinary differential equations. New York, Chapman \& Hall.

[37] Ling D.J., Tao Y.: An analysis of the Hopf bifurcation in a hydroturbine governing system with saturation. IEEE Trans. Energy Convers. 21, 512-515 (2006). DOI: 10.1109/TEC.2005.860407

[38] Ba D.D., Yuan P., Chen D.Y., and et al.: Modeling and analysis of nonlinear hydro-turbine governing system with complex penstocks. Journal of Drainage and Irrigation Machinery Engineering 30, (2012) [in Chinese]. DOI: 10.3969/j.issn.1674-8530.2012.04.011 